JIANG Qingyun, HUANG Xun, CHEN Zhuohao

\title{
Antecedents and consequences of consumers' trust in electronic intermediaries: An empirical study of hotel booking websites
}

\author{
(C) Higher Education Press and Springer-Verlag 2009
}

\begin{abstract}
Electronic intermediaries are recognized as one of the most significant B2C business models in the Internet era. A trustworthy intermediary website functions as both an information intermediary and a credibility intermediary. Given the critical role of trust in driving online purchase behaviors, the technology acceptance model (TAM) has been applied to investigating the impact of technology on online trust from the perspective of users' perception of Web interface. However, consumers' trust in an electronic intermediary derives from not only technological factors, but also factors of brand reputation and consumers' individual experiences. We conducted an experiment in the context of hotel booking websites. Results based on structural equation modeling indicate that the impact of an intermediary's reputation exceeds that of technology acceptance. Besides, reputation sum and reputation distance, which stand for synthesis effect and the cask effect respectively, are the two mechanisms of trust transfer.
\end{abstract}

Keywords trust, electronic intermediaries, reputation sum, reputation distance

摘 要 互联网时代, 网络中介是 $\mathrm{B} 2 \mathrm{C}$ 电子商务的重要形式。一个消费者认可的中介

Translated and revised from Yingxiao Kexue Xuebao 营销科学学报 (Journal of Marketing Science), 2007, 3(2): 56-67

JIANG Qingyun $(\bowtie)$

School of Management, Fudan University, Shanghai 200433, China

E-mail: qyjiang@fudan.edu.cn

HUANG Xun

Department of Marketing, The Chinese University of Hong Kong, Hong Kong SAR, China

E-mail: huangxun@baf.msmail.cuhk.edu.hk

CHEN Zhuohao

Warwick Business School, University of Warwick, Coventry CV4 7AL, UK

E-mail: Zhuohao.Chen@warwick.ac.uk 
网站不仅承担了信息中介的职能, 更扮演了信用中介的角色。信任也被认为是影响网络 购买行为的重要因素。技术采用模型 (TAM) 从网络使用者对网络界面感知的角度研究 了技术对网络信任的影响。消费者对电子中介的信任不仅来自前台的技术层面, 还应包 括后台的品牌机制与消费者自身差异。以酒店预订网站作为切入点, 运用实验法与结构 方程模型, 发现中介网站的声誉对信任的影响超过技术可接受性; 声誉总和与声誉差距 分别对应的协同效应与短板效应是酒店通过中介网站进行信任传递的两种机制。

关键词 信任, 电子中介, 声誉总和, 声誉差距

\section{Introduction}

With the development of the Internet, the number of net-surfers in mainland China reached 338 millions by June, 2009 (CNNIC, 2009). Due to information asymmetry, consumers need to collect relevant information in advance of decisions to reduce uncertainty. Therefore, it is not surprising that tourism and hotel industries are both considered the most suitable industries for electronic services. An increasing number of travelers and businessmen now prefer online booking to traditional offline booking. Internet, as a new commercial platform, inevitably brings some extent of trust loss in the trading process. As a result, many consumers only regard the Internet as a tool for searching information and comparing price, yet still keep doubting to make a real transaction online. It is partly because of lack of physical contact between buyers and sellers, and partly because of the concern about individual privacy. Since the lack of trust is considered to be a great obstacle to online trade, trust has been widely regarded as overridingly important brand equity (Kimery and McCord, 2002). However, little is known about the influential mechanism of consumers' trust in electronic intermediaries.

The purpose of this article is to identify and test factors that influence consumer's trust in electronic intermediaries. Trust in electronic intermediaries simultaneously involves two parties: one is an intermediary website, and the other is hotel. This makes the issue of online trust much more complicated than traditional one. Specifically, we propose that consumers' trust in electronic intermediaries will be affected by three factors, namely brand reputation of two parties (both website and hotel), technology perceived acceptance, and consumers' individual differences.

\section{Literature review}

\subsection{Online trust}

Online trust is defined as the extent of consumers' confidence in an E-merchant's 
competence, benevolence and integrity to perform online transactions successfully (Xiao and Benbasat, 2003; McKnight, Choudhury and Kacmar, 2002). "Competence" is the ability and expertise of a company to fulfill promises made to the customers; "benevolence" looks at the ability of the company to maintain its consumers' interests ahead of its own interests and indicates sincere concern for the benefits of the customers; while "integrity" refers to how consistent, reliable, and honest the company's acts are (Gefen, Karahanna and Straub, 2003; Mayer, Davis and Schoorman, 1995; McKnight, Choudhury and Kacmar, 2002).

The switching cost of online consumption is extremely low compared with that of traditional consumption. Suppose that once consumers distrust an online booking website, they can switch to another one easily. Neither the third-party booking website, nor the hotel-owned booking website, could totally prevent such opportunism behavior (Gefen, Karahanna and Straub, 2003). In such case, the role of trust becomes more salient than ever.

The issue of consumers' trust in hotel electronic intermediaries is even more complicated compared with that of traditional E-retailers. Consumers will not only evaluate whether the third-party intermediary is able to provide them with appropriate hotels, but also care about whether the intermediary holds the spirit of benevolence and integrity. In other words, the electronic intermediary has been regarded as a "social actor" with personality (e.g., kind, honest). The result of previous research also demonstrates that there is no significant difference between online trust and interpersonal trust (Wang and Benbasat, 2005).

On the other hand, trust can be transferred between an intermediary and its clients. The underpinning reason is that consumers tend to treat both as a whole, which means that the reputation of one party could affect another. Although it is suggested in previous study that combining two brands with complementary attributes largely enhances brand value (Park, Sung and Shoker, 1996), relatively little attention has been paid to the specific situation that the difference between two brands is huge.

\subsection{Antecedents of trust}

Previous studies pertaining to the antecedents of trust mainly apply the technology acceptance model (TAM) to make analysis. This model, which consists of perceived usefulness, perceived ease of use, usage intention and usage of information technology (Davis, 1989), is widely used to evaluate the extent to which consumers adopt a new information technology. As TAM mainly emphasizes on the degree of perceived usefulness and perceived ease of use of a certain website from a technological perspective, it fails to examine the influence of brand-related factors and consumers' individual difference. There are only a few exceptions that integrate brand-related factors into framework of trust antecedents. For instance, one of the previous studies suggests that perceived reputation and 
perceived size should be added as antecedents of trust (Koufaris and Hampton-Sosa, 2004). In this study, we further propose that consumers' trust in electronic intermediaries should be thought in a boarder scope with brand-related factors and consumers' individual difference being involved into the integrated model.

It is suggested that antecedents of trust in online brand can be divided into three parts, namely, store-related, website-related and consumer-related determinants (Bramall, Schoefer and McKechnie, 2004). However, to the best of our knowledge, the conceptual model has not been empirically examined.

In accord with the Business-to-Customer mode, antecedents of trust in electronic intermediaries can be divided into two aspects, which are business-based and customer-based. Specifically, the model we propose extends the prior framework of trust's antecedents into three parts, which are company-related factors (background interface), website-related factors (interactive interface), and consumer-related factors (external interface) (Fig. 1).

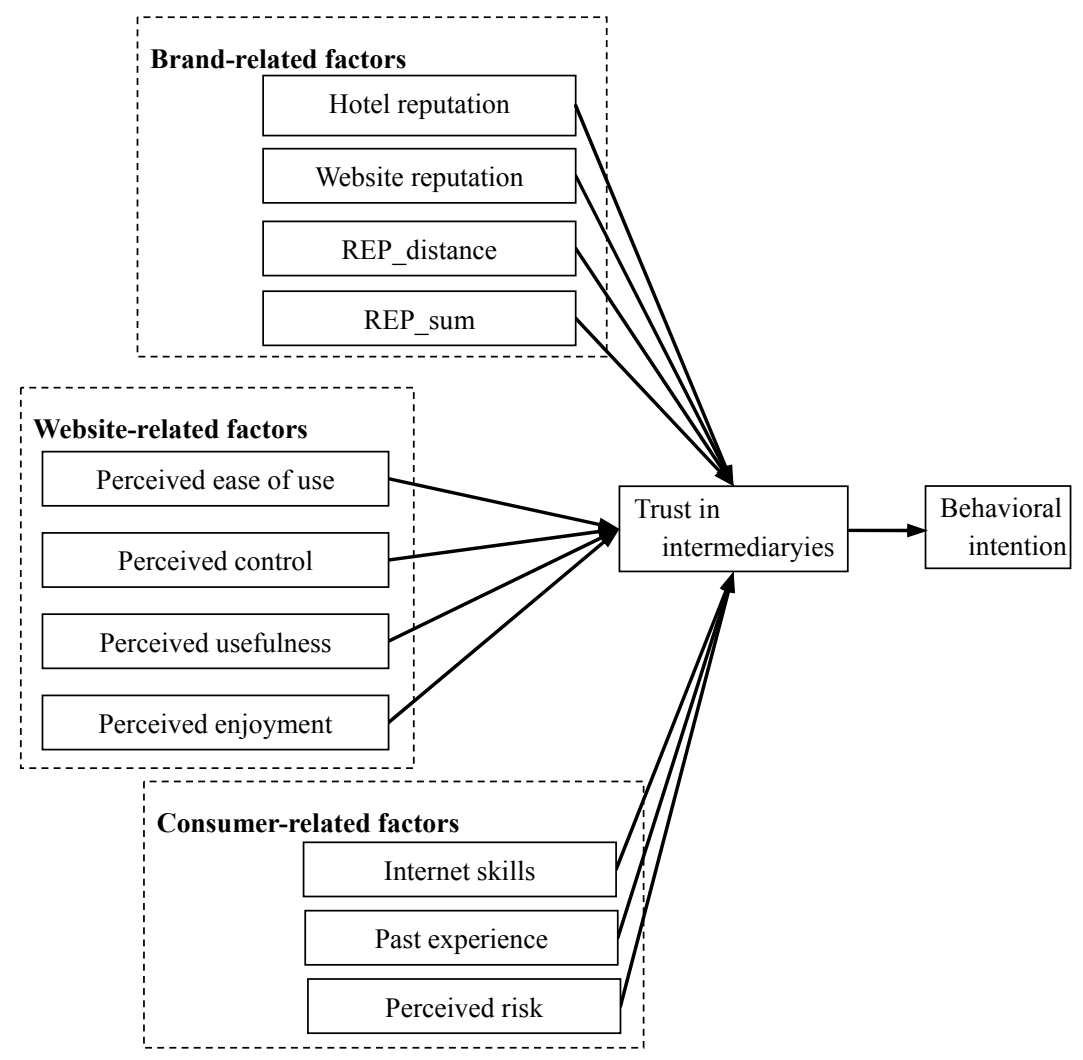

Fig.1 Research model of consumers' trust in electronic intermediaries 


\subsubsection{Company-related factors}

Similar to that of traditional brands, reputation of online brands is also frequently used by online consumers as an indicator of a firm's trustworthiness. Here reputation is defined as the extent to which consumers believe an organization to be honest and concerned about them (Doney and Cannon, 1997). It is generally believed that a positive reputation can be seen as providing assurance of competence, goodwill and integrity, thereby promoting trust, particularly for those first-time transactions (McKnight, Cummings, and Chervany, 1998). Strub and Priest (1976) suggested that trust can be derived from a reliable information source, therefore trust in a relevant third party (e.g., electronic intermediaries) serves as the basis of trust between two parties of transaction. In addition, as the reputation of the cooperator is considered as the basis of cooperation in B2B transactions (Das and Teng, 1998), consumers also likewise have the propensity to trust the company with relative large-scale, simply because large companies have to pay higher costs of reputation loss for dishonest behavior than small ones do (Chen and Dhillon, 2003). Hence, arguments above lead to following hypotheses:

H1 Consumers' trust in an electronic intermediary is positively influenced by the reputation of the hotel.

H2 Consumers' trust in an electronic intermediary is positively influenced by the reputation of the intermediary website.

Besides, different from other e-retailers, hotel booking websites involve two parties, which are electronic intermediary websites and hotels. When both parties share symmetrically high-level reputation, the one with higher reputation will further promote consumers' trust in both parties. It means that reputation sum of a hotel and an electronic intermediary, which is labeled as synthesis effect caused by reputation sum, plays a critical role. On the other hand, when reputation difference between two parties is huge, consumers' trust in both hotel and intermediary will be discounted due to the Cask Effect, even though either party has tremendous high brand awareness. Thus, we propose reputation distance to be another determinant of trust. To sum up arguments above, we propose following hypotheses.

H3 Consumers' trust in an electronic intermediary is positively influenced by the reputation sum of the hotel and electronic intermediary.

H4 Consumers' trust in an electronic intermediary is positively influenced by the reputation distance between the hotel and electronic intermediary.

\subsubsection{Website-related factors}

The technology acceptance model (TAM) developed by Davis (1989) has been 
widely applied in empirical research with regard to individual's acceptance toward websites (Gefen, Karahanna, and Straub, 2003). It is suggested that the extent to individual's acceptance toward certain information technology mainly depends on two factors: (1) usefulness and (2) ease of use. Numerous studies have verified the causality in TAM model. For instance, Perceived usefulness is positively related to usage and usage intention, perceived ease of use is positively related to perceived usefulness (Davis, 1989), and meanwhile, there is a positive correlation between perceived ease of use and usage (Adams, Nelson, and Todd, 1992). Besides, perceived ease of use exerts direct positive influence on trust (Gefen, Karahanna, and Staub, 2003). Based on the original TAM model, Hampton-Sosa and Koufaris's (2005) study adds perceived control and perceived enjoyment into the integrated model and suggests that both of them positively influence trust.

In the current study, we propose that website-related factors include the following four aspects. Firstly, perceived ease of use refers to user's perception of effort required to learn and employ a technology. As we know, customers in offline environment establish trust based on their perception of the salespeople (Ramsey and Sohi, 1997). If a consumer feels the salesperson is easy to approach, his or her trust in this company will emerge consequently (Liu and Leach, 2001). Likewise, it is suggested that customers will trust the website due to their perception of ease of use (Liu and Leach, 2001). Another research stream in communication indicates that good communication between two parties facilitates information transmission, and further influences trust positively (Anderson and Narus, 1990; Selnes, 1998). Thus, if a website owns a higher level of ease of use, consumers will find it easier to communicate with it and consequently trust will be enhanced.

Secondly, perceived control refers to emotional aspects of Internet users toward the environment and behavior, including emotions of calm, anxiety, confusion and control (Koufaris, Kambil, and LaBarbera, 2001). For offline consumers, perceived control exerts positive influence on trust. In particular, a frequently used sales skill is to make customers believe that if they do not make purchasing decision at once they will fail to buy it in the future (loss of control). However, in fact, this tactic will decrease consumers' trust (Clawar, 1977). Similarly, it is predicted that in the online situation, higher level of perceived control will lead to positive consumer attitude and behavior (Koufaris, 2002; Novak, Hoffoman and Yung, 2000). A website with high level of perceived control makes the users believe that their behavior will result in certain and stable outcomes (Palmer, 2002).

Thirdly, perceived usefulness refers to user's subjective perception of task usefulness (Hu, Chau and Sheng, 1999; Agarwal and Karahanna, 2000; Koufaris, 2002). In addition to perceived ease of use, perceived usefulness is also 
considered to have a significant impact on users' attitude towards technology. In other words, a safe and efficient shopping experience provided by a website influences consumers' attitude towards this company (Agarwal and Venkatesh, 2002). Perceived usefulness of website is considered to be similar to the professionalism of salesperson in off-line environment. It is widely accepted that online customers tend to attach importance to practical benefits, that is, make the online consumption due to convenience and efficiency (Childers et al., 2001). Therefore, a useful website will be positively perceived by online customers (Hampton-Sosa and Koufaris, 2005).

Last, perceived enjoyment is used to evaluate attractiveness of website, which is affective based. In the context of offline environment, a pleasant interaction with salespeople significantly and positively influences consumers' trust (Nicholson, Compeau and Sethi, 2001). Even in the online situation, perceived enjoyment may exert important influence on customers' attitude and behavior, such as increasing buying intention (Jarvenpaa, Tractinsky and Vital, 2000; Koufaris, Kambil and Labarbera, 2001) and repurchase intention (Koufaris, 2002).

The discussion leads to the following hypotheses:

H5 Consumers' trust in an electronic intermediary is positively influenced by perceived control of the electronic intermediary.

H6 Consumers' trust in an electronic intermediary is positively influenced by perceived ease of use of the electronic intermediary.

H7 Consumers' trust in an electronic intermediary is positively influenced by perceived usefulness of the electronic intermediary.

H8 Consumers' trust in an electronic intermediary is positively influenced by perceived enjoyment of the electronic intermediary.

\subsubsection{Consumer-related factors}

Factors related to consumers include computer skill, previous experience and perceived risk. Computer skill refers to individual's judgment on their ability of computer usage (Compeau and Higgins, 1995). The definition has been extended to explain users' experience, attitude and intention (Hoffman and Novak, 1996). Previous studies demonstrate that Internet skills help reduce consumers' anxiety about using computer (Novak, Hoffoman and Yung, 2000). Nevertheless, it does not mean that higher computer skill necessarily leads to higher website attractiveness. In some cases, for instance, computer expert might feel website boring and naive just because it is too simple.

Another factor is whether the consumer has similar experience in purchasing product with direct sale in the past. It is found that positive experiences reinforce a consumer's trust in other interactive selling environments (Eastlick and Liu, 1997).

Besides, trust is also linked to consumer's perceived risk in online purchase. 
Koufaris's (2002) study suggested that the lower a consumer perceives the risk, the higher his or her trust will be. Distrust mainly comes from anxiety about abuse of private information.

Based on the arguments above, we propose following hypotheses.

H9 Consumers' trust in an electronic intermediary is positively influenced by their level of computer skills.

H10 Consumers' trust in an electronic intermediary is positively influenced by their previous experience.

H11 Consumers' trust in an electronic intermediary is positively influenced by their perceived risk.

Finally, the level of trust directly influences consumer's booking intention (Hampton-Sosa and Koufaris, 2005). That is,

H12 Consumers' trust in an electronic intermediary positively influences their booking intention.

\section{Methodology}

\subsection{Design}

This study mainly investigated consumers' brand trust, brand attitude, and purchase (booking) intention in various situations. Data collection was based on factorial experiment design, in which participants were required to read a stimulus with scenario and play a role, and then to answer several questions according to given information. Factorial experiment design was applied due to such advantages as ease of control and relatively low cost. This study employed a 2 (website reputation: high vs. low) $\times 2$ (hotel reputation: high vs. low) $\times 2$ (cooperation manner: highlight brand vs. highlight website) design (see Table 1).

Table 1 Experiment design

\begin{tabular}{cccl}
\hline Group No. & Hotel reputation & Website reputation & \multicolumn{1}{c}{ Cooperation manner } \\
\hline 1 & High & High & Highlighting hotel \\
2 & High & Low & Highlighting hotel \\
3 & High & High & Highlighting website \\
4 & High & Low & Highlighting website \\
5 & Low & High & Highlighting hotel \\
6 & Low & Low & Highlighting hotel \\
7 & Low & High & Highlighting website \\
8 & Low & Low & Highlighting website \\
\hline
\end{tabular}


Thus, there were eight different versions of questionnaires in total. All stimulating materials were based on existing website and adopted for experimental need. Before formal experiment procedure, a focus group with six MBA students who had online booking experience before was conducted. In terms of interview results, "Beijing Hilton Hotel" (hotel) and "Ctrip" (intermediary website) were chosen to represent high-reputation hotel and website respectively, and "Beijing Guiguo Hotel" (hotel) and "Tehao" (intermediary website) were randomly chosen from the Internet to represent low-reputation hotel and website. In our focus group, none of the respondents expressed that they had heard of the latter two brands before.

Besides, we manipulated the way of cooperation between a hotel and an intermediary. For the situation that both brands were strong with hotel brand highlighted, both brand logos were put together and a statement of "business partner of XX hotel" appeared below them. If an unknown website was designed to cooperate with a famous hotel, the website name was not emphasized and hotel name stood out in the interface webpage instead. In contrast, if an intermediary was highlighted, then no matter the hotel brand was well-known or not, only the website brand was stressed.

\subsection{Measures}

The measurement of trust was adapted from previous studies. Trust in current study included three dimensions which were competence, benevolence and integrity, each had three items (Wang and Benbasat, 2005; Hampton-Sosa et al., 2005). Then the respondents were required to evaluate items of "company-related factors", "website-related factors" and "consumer-related factors". The items of company-related factors included hotel reputation, website reputation and reputation distance. The items of website-related factors were adapted from previous studies (Wang and Benbasat, 2005). And the items of consumer-related factors covered skills, experience and perceived risk (Hampton-Sosa and Koufaris, 2005; Shimp and Bearden, 1982). All the items were measured in 7-point Likert scales.

\subsection{Data collection}

Participants were MBA and EMBA students of a university located in Shanghai. It is indicated that if subjects of student sample are familiar with specific experiment context or have similar experience before, a satisfactory external validity will be guaranteed (Shuptrine, 1975). In the current study, 75.8\% effective respondents reported that they had experience of online booking in the past year, and $23.0 \%$ had booked even over 5 times in this period. Thus, the 
samples we chose were very familiar with hotel online booking and therefore were representative for our study.

In order to reduce the number of samples needed, each respondent was required to assess two scenarios. Particularly, high (vs. low) reputation hotel occurred once, high (vs. low) reputation website occurred once as well. The order of two scenarios was also counterbalanced to avoid order bias.

In total, we distributed $320(8$ versions $\times 40)$ questionnaires, 312 of which were returned afterwards. After filtering those that were incomplete and obviously unknot seriously answered, a total of 279 effective samples were returned (with an effective respondent rate of $89.4 \%$ ). In our effective samples, $72.1 \%$ of respondents were male, $52.9 \%$ of them were between $30-39$ years old, and over $80 \%$ of them got average monthly salary over 8000 RMB. The results of ANOVA showed that sex, age, experience and salary did not make significant difference.

Preliminary analysis failed to support that cooperation manner, that is, either highlighting hotel brand or website brand influenced consumers' online trust. Thus, in the following analysis, we mainly examined how antecedents of online trust varied in different conditions of hotel and website combination.

\section{Results}

\subsection{Reliability, validity, and scale revision}

To assess the reliability of our measures, we calculated Cronbach's alpha coefficients for each construct. All alpha scores were satisfactory, with most of value greater than 0.80 . Lower indices of perceived control and Internet skills were also over 0.70 , which were acceptable as well. As for validity, results of KMO and Bartlett's Test were both good. Using SPSS 11.5, we report the value of Cronbach's alpha, KMO, Bartlett's Test significant level and the average variance extracted in Table 3.

Besides, we developed several new variables to facilitate our analysis. Following we provide detailed instructions.

(1)Reputation sum, reputation distance and reputation fit

In our questionnaire, we measured reputation of hotel and website in four dimensions, which were brand favorability, brand awareness, industry leadership, and scale. They were labeled as $R E P_{-} H_{i}(i=1,2,3,4)$ and $R E P_{-} W_{i}(i=1,2,3,4)$ respectively.

Reputation sum referred to the four new observed variables that summed up the scores of hotel and website in all four dimensions, namely, $\operatorname{REPSUM}_{i}=$ $R E P{ }_{-} H_{i}+R E P{ }_{-} W_{i}(i=1,2,3,4)$. 
Reputation distance referred to the results of subtracting the score of hotel reputation from website reputation in all four dimensions, which indicated the degree of how hotel brands depended on website brands. Namely, REPDIS $S_{i}=$ $R E P \_W_{i}-R E P H_{i}(i=1,2,3,4)$.

Reputation fit was the reversed score of the absolute value of reputation distance, namely, $R E P F I T_{i}=8-\left|R E P D I S_{i}\right|$. Through structual equation modeling examination, this reputation fit was highly correlated with that was directly measured in questionnaire $(b=0.555)$.

(2)Dimensions of trust

Applying exploratory factor analysis, we only extracted a single dimension from nine items of trust, which illustrated high consistency of these items. Thus, we simplified the trust construct from a three-dimensional construct measured by nine items to a three-item construct. The score of each new item was replaced by the mean of the three corresponding original items.

(3)Website-related factors

Based on TAM model, we designed 14 items about website-related factors. Since deleting the second item of perceived control could significantly increase its construct reliability, we removed this item from the scale in the process of data analysis. In addition, since perceived ease of use, perceived usefulness and perceived enjoyment could not be extracted by exploratory factor analysis. In other words, they were all loaded in a same factor, thus we combined them together and labeled it as a new variable "perceived acceptance" with three items. The score of each item was replaced by the mean of the three corresponding original items.

Table 3 Construct reliability and validity

\begin{tabular}{lccccc}
\hline & & \multicolumn{2}{c}{ Reliability } & \multicolumn{2}{c}{ Validity } \\
\cline { 2 - 6 } & Items & Cronbach's $\alpha$ & KMO & Bartlett's test sig. & $\begin{array}{c}\text { Average variance } \\
\text { extracted \% }\end{array}$ \\
\cline { 2 - 6 } Trust & 9 & 0.9508 & 0.914 & 0.000 & 86.51 \\
$\quad$ Competence & 3 & 0.9093 & 0.722 & 0.000 & 84.69 \\
$\quad$ Benevolence & 3 & 0.9339 & 0.738 & 0.000 & 88.35 \\
$\quad$ Integrity & 3 & 0.8845 & 0.737 & 0.000 & 81.26 \\
Company-related & 11 & & & & \\
$\quad$ Website reputation & 4 & 0.9740 & 0.872 & 0.000 & 92.78 \\
$\quad$ Hotel reputation & 4 & 0.9803 & 0.868 & 0.000 & 94.42 \\
$\quad$ Reputation fit & 3 & 0.9292 & 0.756 & 0.000 & 87.61 \\
Website-related & 13 & & & & \\
$\quad$ Perceived control & 2 & 0.7931 & 0.500 & 0.000 & 58.24 \\
$\quad$ Perceived ease of use & 4 & 0.8953 & 0.791 & 0.000 & 76.15 \\
$\quad$ Perceived usefulness & 4 & 0.9432 & 0.829 & 0.000 & 85.48 \\
$\quad$ Perceived enjoyment & 3 & 0.9452 & 0.741 & 0.000 & 90.14 \\
Consumer-related & 6 & & & & \\
\hline
\end{tabular}




\begin{tabular}{lccccc}
\hline & & \multicolumn{2}{c}{ Reliability } & \multicolumn{2}{c}{ Validity } \\
\cline { 3 - 6 } & Items & Cronbach's $\alpha$ & KMO & Bartlett's test sig. & $\begin{array}{c}\text { Average variance } \\
\text { extracted \% }\end{array}$ \\
Skills & 3 & 0.9061 & 0.712 & 0.000 & 84.29 \\
Experience & 2 & 0.7362 & 0.500 & 0.000 & 79.13 \\
Perceived risk & 1 & - & - & 0.000 & - \\
Booking intention & 4 & 0.9448 & 0.833 & 0.000 & 85.84 \\
\hline
\end{tabular}

\subsection{Hypothesis testing}

Using structural equation modeling software AMOS 5.0, we examined the hypothetical relationships between latent variables. Test results of hypotheses are demonstrated in Table 4.

Table 4 Hypotheses testing $(N=279)$

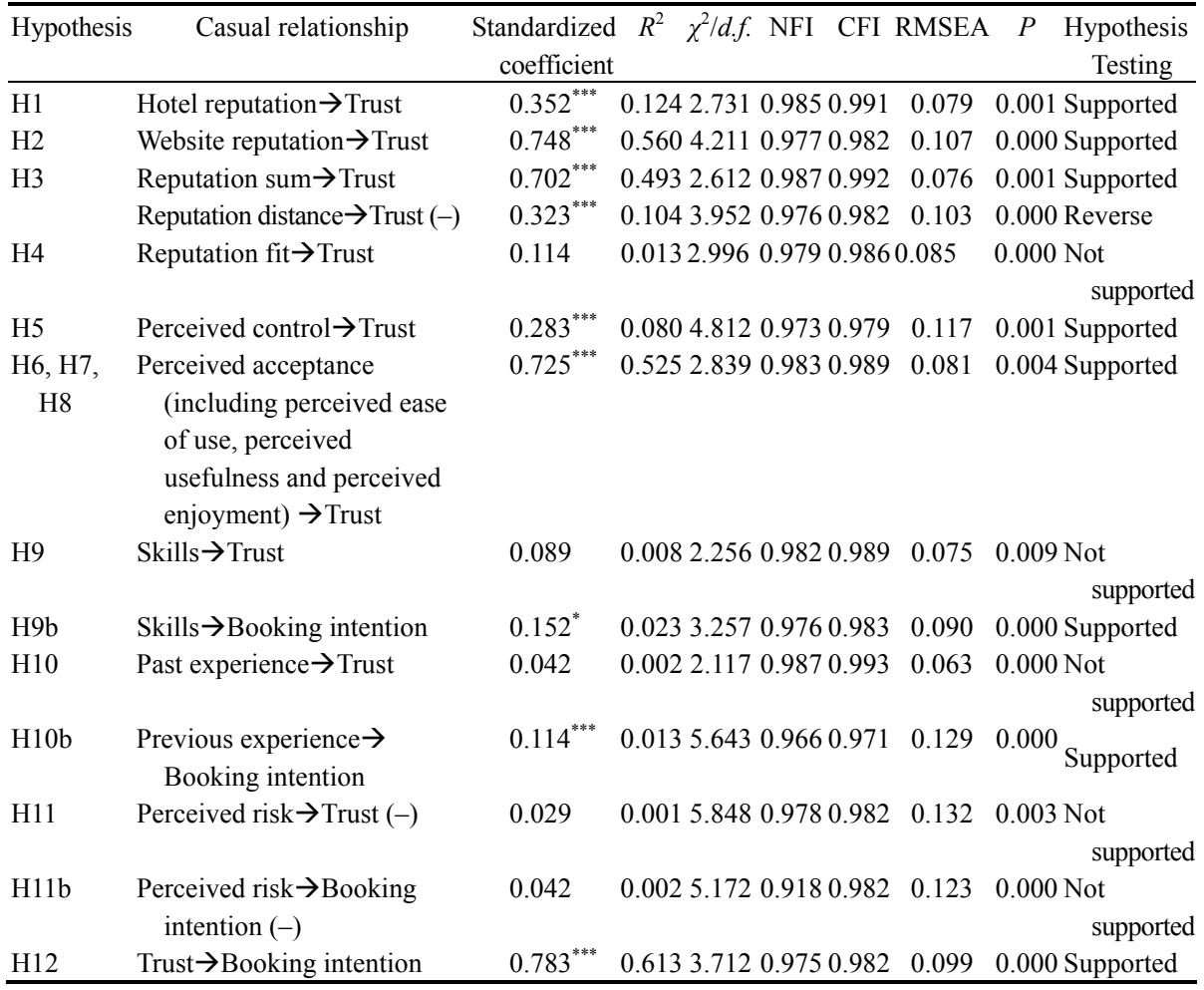

Note: ${ }^{*}$ indicates $p<0.05,{ }^{* *}$ indicates $p<0.01,{ }^{* * *}$ indicates $p<0.001$.

Firstly, in terms of brand aspect, both website reputation and hotel reputation positively influence consumers' trust. Notably, the standardized coefficient of the 
relationship from website reputation to trust $(b=0.748)$ is much greater than that of the relationship from hotel reputation to trust $(b=0.352)$. In addition, the mechanisms of reputation sum and reputation distance are also supported by the model. However, data does not support the relationship between reputation fit and trust. In other words, consumers do not care about whether hotel reputation and website reputation is match or not when they reserve hotel online. Instead, they have concerns about reputation of both website and hotel, namely, whether both parties are strong enough and whether they are dependent on each other. It should be noted that negative influence of reputation distance on trust is proposed in null hypothesis (H4), but actually we find an opposite result, namely, reputation distance positively impacting trust. As we used the score of subtracting hotel reputation from website reputation to measure reputation distance, this finding may suggest that the intermediary website plays a central role in online booking behavior.

Secondly, in terms of website aspects, perceived acceptance (including perceived ease of use, perceived usefulness, and perceived enjoyment) exerts strong positive impact on consumers' trust $(b=0.725)$. Besides, perceived control, which is another variable from TAM, also positively influences trust.

Last, from the aspect of consumer, none of Internet skills, previous experience and perceived risk indicates any positive influence on consumers' trust. Nevertheless, the results of three supplementary examinations (H9b, H10b and $\mathrm{H} 11 \mathrm{~b}$ in Table 4) indicate that skills and previous experience have direct positive influences on booking intention, but perceived risk do not. Taken above, it is implied that consumers' skills and experience do not enhance consumers' trust in a specific website. Instead, they make consumers feel confident in online booking, therefore lead to higher booking intention.

\subsection{Structural equation modeling}

After path analysis above, finally we have an integrated structural equation model with a good overall fit (see Fig. 2).

(1)Antecedents of intermediary trust

The structural equation model demonstrates that consumers' trust in specific an electronic intermediary website is derived from three aspects, which are website reputation, hotel reputation and perceived acceptance of website. In particular, website reputation and hotel reputation influence trust through two mechanisms labeled as reputation sum and reputation distance, and perceived interface acceptance exerts direct influence on trust.

In our model, we allow a certain degree of collinearity because it happens frequently that a website with high reputation usually makes the interface more 
friendly, thus consumers would like to accept it more easily as a result. In fact, perceived acceptance has significantly positive correlations with reputation sum and reputation distance ( $b=0.58$ and 0.37 , respectively). After collinearity being excluded, reputation sum has the greatest impact on consumers' trust in intermediary $(b=0.47)$, followed by perceived acceptance $(b=0.42)$ and reputation distance $(b=0.20)$.

Plus, it should be pointed out that, although there is significant impact of perceived control on trust in separate regression analysis, the path from perceived control to trust is not significant in structural equation modeling due to the involvement of other variables. In order to simplify our model, we remove this variable in the final model.

(2)Antecedents of behavioral intention

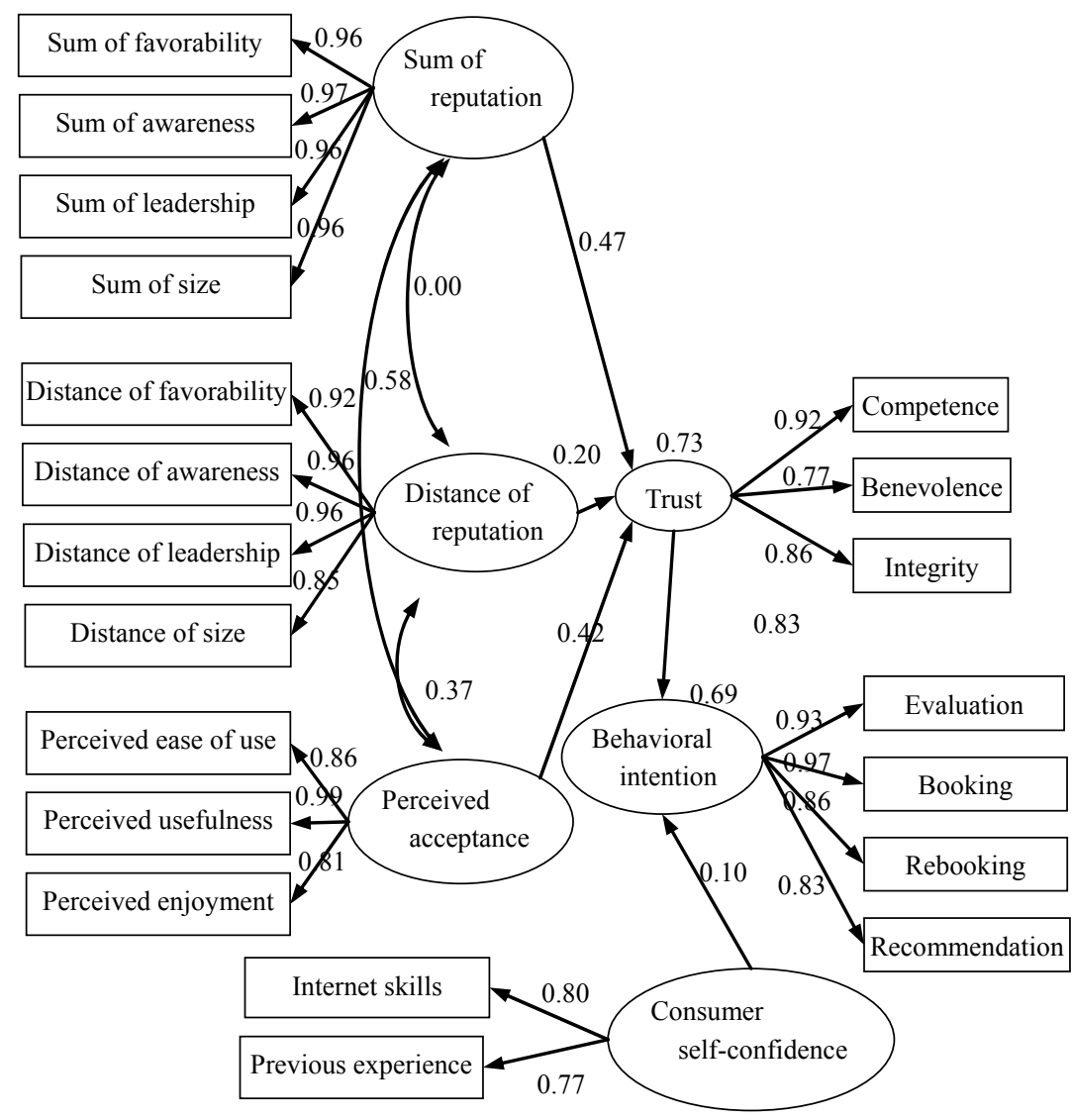

Fig. 2 Integrated Model of Consumers' Trust in Electronic Intermediary Website Note: $N=279 \quad \chi^{2}=436.870 \quad d_{.} .=162 \quad \chi^{2} / d_{.} .=2.697 \quad$ NFI $=0.937 \quad$ CFI $=0.959$ RMSEA $=0.078 \quad P=0.000$. 
The antecedents of behavioral intention to book hotels online mainly come from two aspects. The first, as the more important one, is consumers' trust in intermediary website, with a high path coefficient of 0.83 . The other is derived from a consumer-related latent variable, which includes two dimensions of internet skills and previous experience. We name this latent variable as consumers' self-confidence in internet. Internet skills and previous experience help reinforce such self-confidence. Therefore, confidence in intermediary, i.e. trust, and confidence in self ability together lead to higher online booking behavioral intention.

\section{Conclusion and discussion}

\subsection{Conclusion}

By path analysis and structural equation modeling, we can draw conclusions in three aspects.

(1) In the antecedents of online trust, the impact of brand aspect is greater than that of technology aspect.

Previous studies on online trust (e.g., TAM) mainly emphasize on the influence of consumers' perceived acceptance of technology on online trust. However, our study points out that although technology-related factors play an indispensable role in forming online trust, the reputation of intermediary website and hotel seems even more important. The impact of website reputation on online trust, to which previous research has not paid enough attention, is greater than that of perceived acceptance of webpage. Meanwhile, there also exists high correlation between website reputation and perceived acceptance. On the one hand, perceived acceptance of interface can be regarded as a signal of website reputation. On the other hand, high reputation brings the halo effect, which makes consumer evaluate perceived acceptance to a higher degree.

(2) Consumers evaluate intermediary behavior through two mechanisms: reputation sum and reputation distance.

Considering the experimental context is about online hotel booking behavior, the impact of website reputation is greater than that of hotel reputation on trust formation. We identify "reputation sum" and "reputation distance" as two mechanisms of how brand reputation influences consumers' trust, which lead to "synthesis effect" and "cask effect" respectively. As the names suggest, reputation sum refers to the sum score of website reputation and hotel reputation, and reputation distance refers to the difference between website reputation and 
hotel reputation. Generally speaking, reputation sum has a greater influence on trust than reputation distance does. It implies that a higher trust is most likely to be formed when a famous website cooperates with a well-known hotel, and is least likely to be formed when an unknown website cooperates with an unknown hotel. In the situation of "famous plus unfamous" combination, a well-known website being the agent of an unfamous hotel is better than a famous hotel being listed on an unfamous website.

(3) Consumer-related factors do not influence trust, but directly exert impact on behavioral intention instead.

The conclusion regarding consumers' internet skills and previous experience is quite interesting. The null hypothesis proposes that trust serves as mediator between consumer-related factors and behavioral intention. Nevertheless, our results suggest that consumer-related factors, as a relatively independent mechanism, directly influence behavioral intention. Therefore, we further propose that consumer-related trust is a concept distinguished with consumers' trust in intermediary website. The former indicates the extent to which a consumer has self-confidence in achieving online booking successfully, while the latter stands for trust in intermediary website and hotel.

\subsection{Grouped model comparison and managerial implications}

Further analysis is conducted by dividing the data into groups in terms of hotel reputation and website reputation. Table 5 shows the comparison analysis.

Firstly, we compare the antecedents of trust between famous and unfamous hotels. For the famous hotels, reputation sum is what consumers care most about followed by interface perceived acceptance and reputation distance. It implies that for those already famous hotels, their reputation plus website reputation is enough to obtain consumers' trust, therefore a friendly interface just serves as the role of icing on the cake. Consequently, we can draw the conclusion that the most effective way to promote those famous hotels is to choose a few well-known intermediary websites as agents. With regard to those less famous hotels, consumers mainly focus on the interface perceived acceptance, which is followed by reputation sum. In this case, reputation distance even does not exert significant impact on trust. Thus, it is necessary for unfamous hotels to develop a friendly and easily accepted interface, which serves as a signal of high reputation, to attract consumers. The higher reputation the intermediary website enjoys, the more trust in the hotels will occur consequently. Therefore, compared with well-known hotels, unfamous hotels rely on intermediary website to a greater extent.

On the other hand, we further compare the antecedents of trust between famous and infamous websites. For famous intermediary websites, the impact of 
interface acceptance is greater than reputation sum. As for less famous website, reputation sum still plays a critical role in trust formation, which means that an unfamous website should seek for powerful business partners (hotels) and promote its brand awareness through marketing communications as such advertising. Once websites have obtained certain reputation, just like what Ctrip and eLong have done, they can further increase consumers' trust by developing friendly and customized interface.

In general, most of the electronic intermediaries in China follow the development pathway from information intermediary, to content provider, and to customized information services provider. In other words, the core competence of electronic intermediary websites firstly stems from lager amount of information and better business partners, next from informative content and considerate services, and last from the webpage with easily accepted interface.

From the perspective of hotels, there is a greater and greater extent to which unfamous hotels rely on intermediary websites with the development of internet. As for those famous hotels, since they have already had an ascendant position, their dependence on websites is only restricted to those websites with equally high reputation.

Table 5 Grouped model comparison

\begin{tabular}{|c|c|c|c|c|c|}
\hline Grouped model & Total & $\begin{array}{r}\text { Famous } \\
\text { hotel }\end{array}$ & $\begin{array}{c}\text { Unfamous } \\
\text { hotel }\end{array}$ & $\begin{array}{l}\text { Famous } \\
\text { website }\end{array}$ & $\begin{array}{r}\text { Unfamous } \\
\text { website }\end{array}$ \\
\hline No. of samples $(N)$ & 279 & 141 & 138 & 140 & 139 \\
\hline Reputation sum $\leftarrow \rightarrow$ Reputation distance & 0.00 & $0.38^{* * *}$ & $0.27^{* *}$ & $-0.46^{* * *}$ & -0.17 \\
\hline Reputation sum $\leftarrow \rightarrow$ Perceived acceptance & $0.58^{* * *}$ & $0.69^{* * *}$ & $0.60^{* * *}$ & $0.42^{* * *}$ & $0.54^{* * *}$ \\
\hline $\begin{array}{l}\text { Reputation distance } \leftarrow \rightarrow \text { Perceived } \\
\text { acceptance }\end{array}$ & $0.37^{* * *}$ & $0.42^{* * *}$ & $0.49^{* * *}$ & $0.27^{* *}$ & $0.21^{*}$ \\
\hline Reputation sum $\rightarrow$ Trust & $0.47^{* * *}$ & $0.46^{* * *}$ & $0.42^{* * *}$ & $0.40^{* * *}$ & $0.61^{* * *}$ \\
\hline Reputation distance $\rightarrow$ Trust & $0.20^{* * *}$ & $0.23^{* * *}$ & 0.07 & $0.17^{*}$ & $0.26^{* * *}$ \\
\hline Perceived acceptance $\rightarrow$ Trust & $0.42^{* * * *}$ & $0.29^{* * *}$ & $0.56^{* * *}$ & $0.60^{* * *}$ & $0.27^{* * *}$ \\
\hline Trust $\rightarrow$ Behavioral intention & $0.83^{* * *}$ & $0.80^{* * *}$ & $0.86^{* * *}$ & $0.81^{* * *}$ & $0.76^{* * *}$ \\
\hline $\begin{array}{l}\text { Consumer self-confidence } \rightarrow \text { Behavioral } \\
\text { inattention }\end{array}$ & $0.10^{*}$ & $0.17^{*}$ & 0.03 & 0.18 & 0.03 \\
\hline Average variance extracted of trust & 0.73 & 0.67 & 0.83 & 0.74 & 0.67 \\
\hline $\begin{array}{l}\text { Average variance extracted of behavioral } \\
\text { intention }\end{array}$ & 0.69 & 0.67 & 0.74 & 0.70 & 0.58 \\
\hline$\chi^{2} / d . f$. & 2.697 & 2.199 & 2.354 & 2.174 & 1.945 \\
\hline NFI & 0.937 & 0.892 & 0.894 & 0.893 & 0.906 \\
\hline CFI & 0.959 & 0.938 & 0.936 & 0.939 & 0.952 \\
\hline RMSEA & 0.078 & 0.093 & 0.099 & 0.092 & 0.083 \\
\hline
\end{tabular}

Note: ${ }^{*}$ indicates $p<0.05,{ }^{* *}$ indicates $p<0.01,{ }^{* * *}$ indicates $p<0.001$. 


\subsection{Limitations and further research directions}

Current research demonstrates how intermediary website reputation and hotel reputation influence consumers' trust in intermediary interface. It is pointed out that, as the development of internet in China is far from mature, reputation factors should be given higher priority in comparison with interface perceived acceptance. However, it can not be ignored that website reputation is highly and positively correlated with interface perceived acceptance. Thus, further research is needed to examine the relationship between these two factors: are the variables related to TAM the antecedents of website reputation? Or, website existing reputation leads consumers to a higher evaluation on perceived acceptance? In addition, are there any other factors could exert influence on intermediary website reputation? Namely, how does intermediary website accumulate its reputation? Answers to these questions await further research.

\section{References}

Adams D A, Nelson R, Todd P A (1992). Perceived usefulness, ease of use, and usage of information technology: A replication. MIS Quarterly, 16: 227-247

Agarwal R, Karahanna E (2000). Time flies when you're having fun: cognitive absorption and beliefs about information technology usage. MIS Quarterly, 24(4): 665-694

Agarwal R, Venkatesh V (2002). Assessing a firm's web presence: A heuristic evaluation procedure for the measurement of usability. Information Systems Research, 13(2): 168-186

Anderson J C, Narus J A (1990). A model of distributor firm and manufacturer firm working partnerships. Journal of Marketing, 54(1): 42-58

Bramall C, Schoefer K, McKechnie S (2004). The determinants and consequences of consumer trust in E-retailing: A conceptual framework. Irish Marketing Review, 17: 13-22

Clawar S S (1977). Patterns of intimidating the consumer. Journal of Consumer Affairs, 11(2): $86-93$

Chen S C, Dhillon C S (2003). Interpreting dimensions of consumer trust in E-commerce. Information Technology and Management, 4: 303-318

Childers T L, Carr C L, Peck J, et al. (2001). Hedonic and utilitarian motivations for online retail shopping behavior. Journal of Retailing, 77(4): 421-423

Compeau D R, Higgins C A (1995). Computer self-efficacy: Development of a measure and initial test. MIS Quarterly, 19(2): 189-211

Das T K, Teng B S (1998). Between trust and control: Developing confidence in partner cooperation in alliances. Academy of Management Review, 23(3): 491-512

Davis F D (1989). Perceived usefulness, perceived ease of use, and user acceptance of information technology. MIS Quarterly, 13: 319-340

Doney P M, Cannon J P (1997). An examination of the nature of trust in buyer-seller relationships. Journal of Marketing, 61(2): 35-51

Eastlick M A, Liu M (1997). The influence of store attitudes and other nonstore shopping patterns on patronage of television shopping programs. Journal of Direct Marketing, 2(3): 
$14-24$

Gefen D, Karahanna E, Straub D W (2003). Trust and TAM in online shopping: An integrated model. MIS Quarterly, 1(27): 51-90

Hampton-Sosa W, Koufaris M (2005). The effect of web site perceptions on initial trust in the owner company. International Journal of Electronic Commerce, 10(1): 55-81

Hoffman D L, Novak T P (1996). Marketing in hypermedia computer mediated environments: Conceptual foundations. Journal of Marketing, 60(3): 50-68

Hu P J, Chau P Y K, Sheng O R L, Tam K Y (1999). Examining the technology acceptance model using physician acceptance of telemedicine technology. Journal of Management Information Systems, 16(2): 91-112

Jarvenpaa S L, Tractinsky N, Vital M (2000). Consumer trust in an internet store. Information Technology and Management, (1): 45-71

Kimery K M, McCord M (2002). Third-party assurances: Mapping the road to trust in E-retailing. Journal of Information Technology Theory and Application, 4(2): 63-82

Koufaris M (2002). Applying the technology acceptance model and flow theory to online consumer behavior. Information Systems Research, 13(2): 205-223

Koufaris M, Kambil A, Labarbera P A (2001). Consumer behavior in web-based commerce: An empirical study. International Journal of Electronic Commerce, 6(2): 131-154

Koufaris M, Hampton-Sosa W (2004). The development of initial trust in an online company by new customers. Information \& Management, 41(3): 377-397

Liu A H, Leach M P (2001). Developing loyal customers with a value-adding sales force: Examining customer satisfaction and the perceived credibility of consultative salespeople. Journal of Personal Selling \& Sales Management, 21(2): 147-156

Mayer R C, Davis J H, Schoorman F D (1995). An integrative model of organizational trust. Academy of Management Review, 3(20): 709-734

McKnight D H, Choudhury V, Kacmar C (2002). Developing and validating trust measures for E-commerce: An integrative typology. Information Systems Research, 3(13): 3343-3359

McKnight D H, Cummings L L, Chervany N L(1998). Initial trust formation in new organizational relationships. Academy Management Review, 23: 473-490

Nicholson C Y, Compeau L D, Sethi R (2001). The role of interpersonal liking in building trust in long-term channel relationships. Journal of the Academy of Marketing Science, 29(1): $3-15$

Novak T P, Hoffoman D L, Yung Y F (2000). Measuring the customer experience in online environments: A structural modeling approach. Marketing Science, 19(1): 22-42

Palmer J W (2002). Web site usability, design, and performance metrics. Information Systems Research, 13(2): 151-167

Park C W, Sung Y J, Shoker A D (1996). Composite branding alliances: An investigation of extension and feedback effects. Journal of Marketing Research, 33: 453-466

Ramsey R P, Sohi R S (1997). Listening to your customers: The impact of perceived salesperson listening behavior on relationship outcome. Journal of the Academy of Marketing Science, 25(2): 127-137

Selnes F (1998). Antecedents and consequences of trust and satisfaction in buyer-seller relationships. European Journal of Marketing, 32(3/4): 305-322

Shimp T A, Bearden W O (1982). Warranty and other extrinsic cue effects on consumers' risk perceptions. Journal of Consumer Research, 9: 38-46

Shuptrine F K (1975). On the validity of using students as subjects in consumer behavior investigations. Journal of Business, 48: 383-390

Strub P J, Priest T B (1976). Two patterns of establishing trust: The marijuana user. 
Sociological Focus, 9(4): 399-411

Wang W, Benbasat I (2005). Trust in and adoption of online recommendation agents. Journal of Association for Information Systems, 6(3): 72-101

Xiao S, Benbasat I (2003). The formation of trust and distrust in recommendation agents in repeated interactions. Proceedings of the 5th international conference on electronic commerce, Pittsburgh, America, 287-293

中国互联网络信息中心 (CNNIC) (2006). 第 18 次中国互联网络发展统计报告, http://news.xinhuanet.com/tech/2006-07/19/content_4854427.html , 2006-7-19 